\title{
COVID-19 Status in Nepal and the Way Forward
}

\section{Pravash Budhathoki ${ }^{1}$, Dhan Bahadur Shrestha ${ }^{2}$, ${ }^{\star}$ Sitaram Khadka ${ }^{3,4}$, Santoshi Giri ${ }^{5}$}

\section{Author Info:}

'Dr Iwamura Memorial Hospital, Bhaktapur, Nepal

${ }^{2}$ Mangalbare Hospital, Morang, Nepal

${ }^{3}$ Shree Birendra Hospital; Nepalese Army Institute of Health Sciences, Kathmandu, Nepal

${ }^{4}$ Punjab University College of Pharmacy, University of the Punjab, Lahore, Pakistan

${ }^{5}$ Nepal Public Health Research and

Development Center, Kathmandu, Nepal

\section{*Corresponding Author:}

Sitaram Khadka

E-mail/contact:

sitaramkhadka@gmail.com

00977-9851077589

ORCID:

https://orcid.org/0000-0002-0251-3817

\begin{abstract}
Coronavirus disease (COVID-19) is declared a pandemic on 11 March 2020 due to its global spread. The progression of disease is still at the same speed and the low and middle income countries (LMICs) like Nepal are in a vulnerable state. Starting from the first reported case in January, there have been a total 99 cases as of 7 May 2020 with the chance of further increment in number, but there is no death due to COVID-19 at all in Nepal. The expansion and decentralization of healthcare facilities along with lockdown approach are praiseworthy to contain and treat the disease, however there is still a lack of adequate resources for effective enrichment of healthcare facilities. Poor border security, lack of sufficient health resources, proper health waste management, and social stigmatization remain a major problem for the country. There is not any approved therapy for the treatment of COVID-19, therefore prevention is the best way of effective management in Nepal. The most valid strategy is the application of preventive measures through hand-washing, social distancing, and increasing mass awareness through audio-visual aids about the disease. Simultaneously, the preparedness for effective treatment strategies and application to every healthcare institution handling COVID-19 cases is mandatory.
\end{abstract}

Keywords: COVID-19; Healthcare facilities; Nepal; Pandemic; Prevention

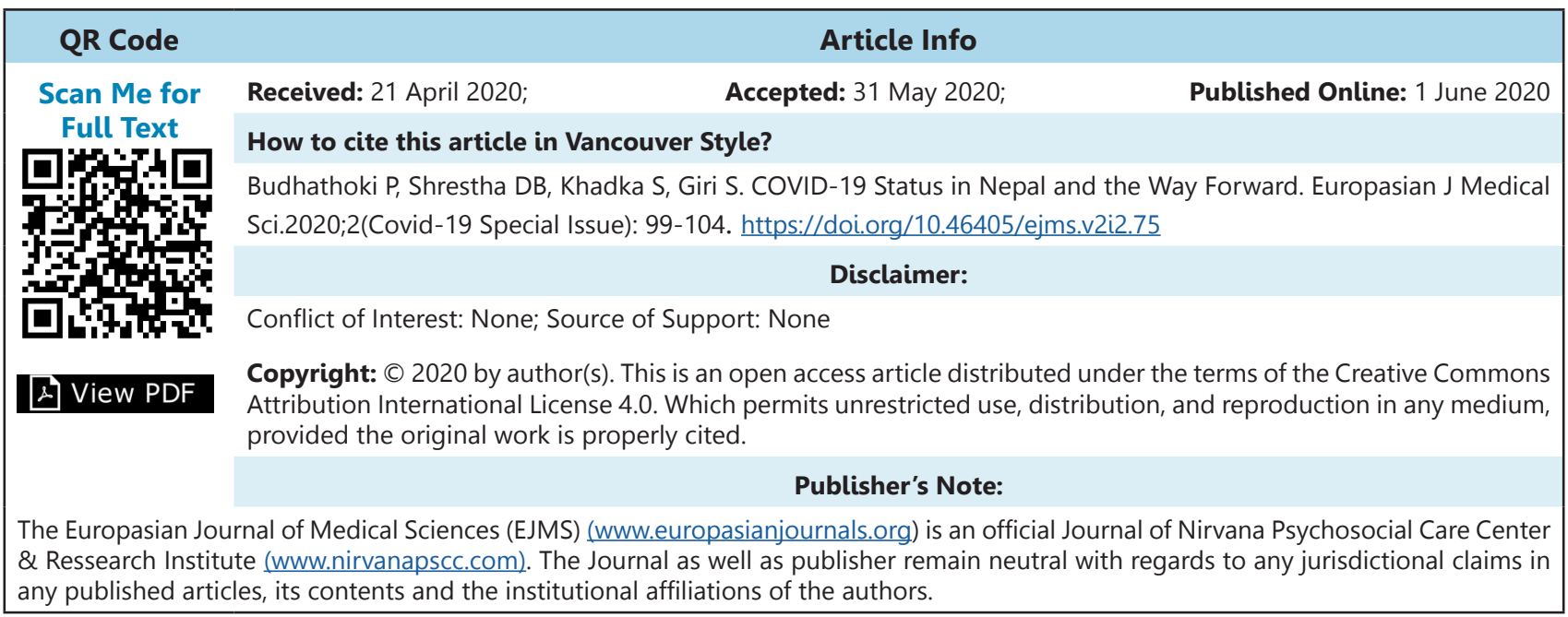




\section{INTRODUCTION}

A group of pneumonia cases were reported from Wuhan, China, in 31 December 2019, which was identified to be due to a coronavirus named severe acute respiratory syndrome coronavirus-2(SARS-CoV-2). The world health organization (WHO) designated the disease as COVID-19 in 11 February 2020, and later declared a pandemic in 11 March 2020 due to its global spread in a very short time. ${ }^{1}$ There have been $3,634,172$ cases worldwide with 251,446 death tolls until 7 May 2020 as per WHO. ${ }^{2}$ It is a respiratory illness, which is transmitted from human to human and is characterized by sometimes asymptomatic to symptomatic nature ranging from mild symptoms like fever, fatigue, dry cough, and myalgia to pneumonia and acute respiratory distress syndrome (ARDS) in severe cases. ${ }^{3}$ The first case in Nepal was reported in 23 January 2020 in a patient emphasizing the role to be played by the LMICs like Nepal for the containment strategy.

\section{STATUS OF COVID-19 IN NEPAL}

As of May 7, 99 cases of COVID-19 have been detected in Nepal5. The summary of the status of the cases is depicted in table 1. According to the latest database updated by Nepal government, 33522 swabs have been collected and sent for investigation and hotline phones have been accessed 2039 times. $^{5}$

- Within the week of the first case identified, Nepal government took various steps for control of COVID-19. ${ }^{6}$

- Opening 5 hospitals and 13 key satellite hospitals with isolation facilities for COVID-19 cases.

- Technical documents tailored for the

Table 1: Status of COVID-19 in Nepal ${ }^{5}$

\begin{tabular}{|c|c|c|c|c|c|c|c|}
\hline $\begin{array}{c}\text { Rapid } \\
\text { Antibody } \\
\text { Tests done }\end{array}$ & \multicolumn{2}{|c|}{$\begin{array}{l}\text { Polymerase chain } \\
\text { reaction }(\mathrm{PCR}) \text { done }\end{array}$} & \multicolumn{3}{|c|}{ Total positive cases(PCR) } & Quarantined & Isolated \\
\hline \multirow{3}{*}{54,093} & Positive & Negative & Recovered & $\begin{array}{l}\text { Under } \\
\text { treatment }\end{array}$ & Deaths & \multirow{3}{*}{17372} & \multirow{3}{*}{133} \\
\hline & 99 & 14410 & 22 & 77 & 0 & & \\
\hline & \multicolumn{2}{|c|}{ Total:14509 } & \multicolumn{3}{|l|}{ Total: 99} & & \\
\hline
\end{tabular}

with a travel history from China and it has been reached 99 till date. ${ }^{4,5}$

This review is aimed at sharing the status of Nepal against COVID-19 race and
Ministry of Health and Population for the investigation and containment of COVID-19. Installation and functioning of thermal scanner at Tribhuvan international airport (TIA) 
- Preparation of the national public health laboratory (NPHL) on January 27 for the diagnosis of COVID-19

- Dedicated ambulance available at TIA for effective patient transfer

- Dissemination of information, education and communication (IEC) material regarding COVID - 19

As different approaches for management, hotline services are introduced to provide information on COVID-19. A treatment protocol has been developed by the Epidemiology and Disease Control Division (EDCD), Nepal, based on the protocol developed by the United Nations Health Agency for the treatment of COVID-19. The border with neighboring countries like India and China has been closed to prevent transmission of disease. ${ }^{7}$ People arriving at the national airport in Kathmandu are checked for viral infection and put into self-quarantine for 14 days. A high-level committee has been formed to better handle the corona virus. A travel ban has been imposed to people from Europe, West Africa, West Asia, Gulf, and Japan on March 20, 2020 as a precautionary measure. Visit Nepal 2020 has been postponed, and the entire country has been put into lockdown since 24 March 2020.8 The Ministry of Health and Population has endorsed a 'six $\mathrm{T}^{\prime}$ strategy (travel registration, testing, tracing, tracking, treatment, and togetherness) to combat the outbreak in Nepal.
Rapid Diagnostic tests have been used since 5 April 2020 in three districts, Kailali, Kanchanpur, and Baglung.9 Government has emphasized on preventive measures like hand-washing and social distancing. The PCR testing has also been expanded from NPHL to a total of 17 different test centers in different provinces.10 At present, 25 hub hospitals are providing services to COVID-19 suspected and confirmed cases throughout the country. ${ }^{5}$

The preparation from different levels for prevention and necessary management are being carried out. Nepal Army has been active in increasing awareness regarding the prevention of COVID-19, preparing quarantines in every province, establishing COVID-19 coordination center, and isolation wards in hospitals.

Nepal Government has designated the armed police hospital, Kathmandu as anti-COVID-19 dedicated facility for the management of COVID-19 cases. Previously, Sukraraj Tropical and Infectious Disease Hospital in Kathmandu as the primary hospital and a temporary hospital in Chitawan as Bharatpur as Corona Special Hospital were there for special management of COVID-19.11,12

\section{ATTITUDE AND BEHAVIOR}

In general, people have been compliant with the government's lockdown and social distancing policies with few exceptions. There has been some stigmatization towards health care providers with some instances of house owners asking them 
to leave their home. In addition, people coming from abroad have been threatened to leave their rented homes and been asked to go for testing despite having no symptoms.13 Some of the recovered patients have voiced about the need for media to avoid providing names and stigmatizing the disease and to be mentally sound to defeat the disease.14 The social, economic, and mental impact on people amid COVID-19 lock down will definitely add extra challenges to the community and nation. Poverty has been a great risk factor for such impact and the government and local responsible citizens are trying to settle down such issues to some extent.

\section{PROBABLE RISK}

As Nepal is landlocked with China and India, there is a high risk for COVID-19 outbreaks and spread. China is the origin of COVID-19 and India is a country where the cases are continuously increasing day by day. The open border and close ties with India puts Nepal at an increased risk despite border closure and improvement in security. Although the tests have been ramped up lately, Nepal still has done fewer tests and the aggressive use of rapid tests has not been advised by WHO which has focused on the use of rapid tests for research purposes mostly. Social stigmatization of COVID -19 has been another risk factor that has hampered basic human rights and affected both patients and health service providers. $^{15}$

As Nepal is among the LMICs with gross national income (GNI) less than \$3,995, the capacity of resources will no longer be sufficient once the outbreak occurs in a large number. ${ }^{16}$ The difficulties faced to manage the COVID-19 due to escalating affected cases along with death tolls in the developed nations sufficiently warns the LMICs like Nepal to be in well protected site by the adequate utilization of resources for preventive aspects. The limited number of healthcare personnel, facilities, and resources like personal protective equipment (PPE), laboratory equipment, medicines, and other necessary resources needed to combat COVID-19 will no longer hold the situation in an effective way. ${ }^{17}$ Delay and hurdles in the availability of such items in Nepal at the central level have been a risk factor for the management of COVID-19. Health care waste management remains another critical hurdle as it has never been of proper standard even in normal scenarios in most of the places. The movement of people to live life from the urban to rural area amid lockdown has also a risk of transmission of disease.

\section{Way Forward}

The limited number of resources in Nepal as compared to that of developed nations is a challenging factor for COVID-19 management. Nepal has to focus more on the preventive aspects because even the developed nations are in an uncontrolled situation due to the rapid spread of this disease. Preventive measures like proper hand-washing, using face masks, goggles, gloves while touching the surface in public 
places, social distancing, quarantine, and isolation are effective ways out. For such activities, proper quarantine and isolation setup, audio-visual educational awareness campaigns, proper communication strategies for preventive measures to make the general public understand the procedure of safety concerns regarding the prevention of virus can be conducted in different places., ${ }^{3,15}$ Safeguarding of all frontline professionals and availability of adequate resources at the national and local level are essential in such crises. Healthcare workers including physicians, pharmacists, nurses, laboratory technologists; every responsible citizens including different influencers, and female community health volunteers ${ }^{19}$ along with the government should work on raising awareness about COVID-19 and help reduce the stigmatization and mental stress reaped from the terror of this disease, and help to manage people under poverty with consideration of social, economic and mental level as well.

\section{TAKE HOME MESSAGE}

Nepal has 99 cases of COVID 19 as of 7 May 2020 and most of the cases are asymptomatic or mild type.

There is no death due to COVID-19 at all. The government is expanding health care through a gradual increase in hub hospitals and testing centers to test, trace, track, and treat cases in addition to lockdown and shut down of international flights. Poor border security, lack of sufficient health resources, proper health waste management, and social stigmatization remain a major problem for the country.

Prevention through hand-washing, proper waste handling, social distancing, environmental hygiene, and increasing mass awareness through audio-visual aids about the disease remains the most valid strategy for a developing nation like ours.

\section{REFERENCES}

1. WHO Timeline - COVID-19. WHO. Published 2020. Accessed May 7, 2020.[Link]

2. Coronavirus (COVID-19). WHO. Published 2020. Accessed May 21, 2020.[Link]

3. Khadka, S., Hashmi, F.K. \& Usman M. Preventing COVID-19 in low- and middle-income countries. Drugs Ther Perspect. 2020;36(6):250252. doi:https://doi.org/10.1007/s40267-02000728-8 [Google Scholar] [PubMed]

4. Bastola, A., Sah, R., Rodriguez-Morales, A. J., Lal, B. K., Jha, R., Ojha, H. C., ... \& Morita K. The first 2019 novel coronavirus case in Nepal. Lancet Infect Dis. 2020;20(3):279-280.[Google Scholar] [PubMed]

5. COVID-19. Government of Nepal, Ministry of Health and Population.. Published 2020. Accessed May 7, 2020.[Link]

6. SitRep\#1; Health Sector Response to Novel Coronavirus (2019-nCoV). Government of Nepal, Ministry of Health and Population. Published 2020. Accessed May 7, 2020.[Link]

7. Hundreds of Nepalese stuck at India border amid COVID-19 lockdown. Al Jazeera.. Published April 1, 2020. [Link]

8. Nepal extends lockdown until April 15 onlinekhabar. Published April 6, 2020. [Link]

9. Rapid coronavirus antibodies tests begin today. The Himalayan TIMES. Published April 5, 2020. [Link]

10. SitRep\#87; Health Sector Response to Novel Coronavirus Disease (COVID-19). Government of Nepal, Ministry of Health and Population. Published 2020. Accessed May 7, 2020. [Link] 
11. APF Hospital Begins Test And Care Of COVID-19. THE RISING NEPAL. Published April 10, 2020. [Link]

12. Mishra, V. P., Paudel, S., Twanabasu, S., Thapa, K., \& Kusma S. Ongoing COVID-19 pandemic: Current Status of Nepal. Eur J Med Sci. 2020;2(1). [Google Scholar]

13. Destigmatizing corona patients. myRepublica. Published April 2, 2020. [Link]

14. Two COVID-19 patients discharged. The Himalayan TIMES. Published April 19, 2020. [Link]

15. Water, sanitation, hygiene and waste management for COVID-19. WHO.. Published 2020. Accessed May 7, 2020. [Link]
16. The World Bank Group. Data. Published 2020. Accessed May 7, 2020. [Link]

17. Marahatta, S. B., Paudel, S., \& Aryal N. COVID-19 Pandemic: What can Nepal do to Curb the Potential Public Health Disaster? J Karnali Acad Heal Sci. 2020;3(1). [Google Scholar]

18. Shahi, P., Tamang, P. D., \& Rokaya YB. What can other countries learn from South Korea's COVID-19 responses? Eur J Med Sci. 2020;2(1). [Google Scholar]

19. Parajuli, S. B., Shrestha, S., Sah, A., Heera, K. C., Amgain, K., \& Pyakurel P. Role of Female Community Health Volunteers for Prevention and Control of COVID-19 in Nepal. J Karnali Acad Heal Sci. 2020;3(1).[Google Scholar] 